\title{
Criptococose cutânea canina: relato de caso
}

\author{
[Canine cutaneous cryptococcosis - Case report]
}

\section{"Relato de Caso/Case Report"}

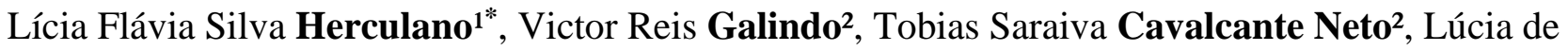 \\ Fátima Lopes dos Santos $^{2}$
}

\begin{abstract}
${ }^{1}$ Residência em Anestesiologia, Universidade Federal de Santa Maria (UFSM), Santa Maria-RS, Brasil. ${ }^{2}$ Faculdade de Veterinária, Universidade Estadual do Ceará (UECE), Fortaleza-CE, Brasil. *Autor para correspondência/Corresponding author: E-mail: tobiasscneto@hotmail.com
\end{abstract}

\section{Resumo}

Criptococose é uma doença multissistêmica que acomete humanos e animais. É transmitida pela inalação de esporos de um fungo da espécie Cryptococcus neoformans que se desenvolve em matéria orgânica, principalmente em fezes de aves e madeira em decomposição. Esta enfermidade é, em geral, de caráter oportunista sendo mais comum em gatos do que em cães. As manifestações clínicas dessa doença variam e podem causar distúrbios oftálmicos, respiratórios, cutâneos e neurológicos. O diagnóstico vai além da avaliação física e anamnese, podendo o médico veterinário solicitar exames micológicos (cultura fúngica e esfregaço de material da lesão), citológicos, histopatológicos, entre outros para especificar qual realmente é a causa do problema e tratar de modo mais adequado possível. O tratamento é baseado no uso de antifúngicos sistêmicos, no entanto, a literatura não relata o tempo mínimo adequado de tratamento, indicando manter o protocolo terapêutico por mais 30 ou 60 dias após melhora do quadro clínico e resultados de exames negativos para criptococose. O presente trabalho tem o objetivo de relatar um caso de criptococose cutânea em uma cadela de nove anos da raça Pastor Alemão. A paciente apresentava lesões ulcerativas no membro torácico esquerdo, que causavam dor quando palpadas. $\mathrm{O}$ diagnóstico foi confirmado por cultura fúngica e a terapia foi realizada com itraconazol na dose de $10 \mathrm{mg} / \mathrm{kg}$, via oral (VO), a cada 24h (q24h) inicialmente, fazendo ajustes posteriores para $20 \mathrm{mg} / \mathrm{kg} \mathrm{VO}$, q24h totalizando cinco meses de terapia, resultando em melhora da doença e sem efeitos adversos, para a paciente relatada. Assim, é necessário que exames complementares e diagnósticos mais precisos sejam realizados para contribuírem para uma terapia adequada objetivando a cura clínica.

Palavras-chave: cão; Cryptococcaceae; fungo; triazólicos.

\begin{abstract}
Cryptococcosis is a multisystem disease that affects humans and animals. It is transmitted by the inhalation of spores of Cryptococcus neoformans a fungal species that grows on organic matter, mainly in bird feces and decomposing wood. This disease is mainly opportunistic and is more frequently observed in cats than dogs. The clinical manifestations of this disease may vary leading to ophthalmic, respiratory, cutaneous and neurological disorders. The diagnosis goes beyond physical assessment and anamnesis, and the veterinarian may request mycological exams (fungal culture and smear from lesion), cytology, histopathology, among others, to specify what is really the cause of the problem and to treat it in the most appropriate way possible. The treatment is based on systemic antifungals, however, the literature does not report the minimum appropriate treatment time, indicating that the therapeutic protocol should be maintained for another 30 or 60 days after improvement of the clinical condition and negative test results for cryptococcosis. This paper aims to report a case of cutaneous cryptococcosis in a nine-year-old female German Shepherd dog. The patient had ulcerative lesions in the left thoracic limb, which caused pain when touched. The diagnosis was confirmed by fungal culture and therapy was performed with Itraconazole at a dose of $10 \mathrm{mg} / \mathrm{kg}$ orally, q24h initially, making subsequent adjustments to $20 \mathrm{mg} / \mathrm{kg}$ orally, $\mathrm{q} 24 \mathrm{~h}$ totaling five months of therapy, resulting in improvement of the disease and without further side effects for the patient. Therefore, it is required to perform accurate complementary exams and diagnosis in order to contribute to an adequate therapy aiming clinical cure.
\end{abstract}

Keywords: dog; Cryptococcaceae; fungus; triazoles. 


\section{Introdução}

A criptococose é uma micose multissistêmica que acomete humanos e animais, cuja infecção se dá pela inalação de esporos de Cryptococcus neoformans que se desenvolvem em matéria orgânica (excrementos de pássaros, morcegos e eucalipto em decomposição, por exemplo) (Crivellenti e Crivellenti, 2015).

O agente causador da criptococose é uma levedura da classe Bastomycetes, família Cryptococcaceae, gênero Cryptococcus, espécie Cryptococcus neoformans (Quinn et al., 2005).

Este fungo pode ser encontrado em excrementos de pombos, pois a creatinina presente nas excretas dessas aves é usada como substrato pelas leveduras de $C$. neoformans (Quinn et al., 2005). O agente pode persistir no ambiente durante anos em pombais protegidos da luz solar ou de umidade, além disso, outras aves, especialmente araras, periquitos, e cisnes com fezes contaminadas por leveduras de $C$. neoformans também podem contribuir para a disseminação do fungo (Vorathavorn et al., 2013).

Cryptococcus neoformans variedade neoformans possui distribuição mundial, enquanto o C. neoformans variedade gattii possui distribuição mais limitada e está associado com muitos casos descritos na Austrália (Grace, 2009). As variedades neoformans e grubii são cosmopolitas, costumam ser encontradas no solo, em frutas e podem estar presentes nas mucosas oral e nasal e na pele de indivíduos sadios (Juliano et al., 2006).

Após a inalação o agente distribui-se pelo sangue acometendo outros órgãos, principalmente o sistema nervoso central (SNC), pele, linfonodos, ossos olhos, coração, fígado, baço, rins, tireoide, adrenais e até a próstata, sendo esta última considerada como reservatório para a recidiva da enfermidade (Bivanco et al., 2006). Os principais fatores de virulência do Cryptococcus neoformans são a tolerância térmica, os componentes da parede celular e da cápsula, a capacidade de adesão, os receptores de hormônios e a produção de enzimas (Moretti et al., 2008).

No organismo do hospedeiro, os fungos encontram diversos mecanismos, da imunidade inata e da imunidade adquirida, que tentam eliminá-los, atuando por meio de um padrão de resposta Th1 e com liberação de citocinas por estímulos de macrófagos (Moretti et al., 2008). Animais imunocompetentes podem apresentar resposta imune celular efetiva para $C$. neoformans e a disseminação do agente para demais órgãos está associada a defeitos nessa imunidade mediada por células (Quinn et al., 2005). Tanto a parede celular como a cápsula sintetizada pelos fungos são estruturas que os protegem dos ataques do hospedeiro (Moretti et al., 2008). A inibição da fagocitose, bloqueio da fixação de C3 e da via da ativação de complemento pela via clássica, inibição da ligação de $\operatorname{IgG}$ e supressão da proliferação de expressão de moléculas de adesão são alguns dos mecanismos usados para sobrevivência do Cryptococcus neoformans no hospedeiro (Moretti et al., 2008).

Os sinais clínicos podem ser divididos em quatro síndromes principais: respiratória, neurológica, ocular e cutânea, podendo ser encontradas associações destas em um mesmo animal (Marcasso et al., 2005; Queiroz et al., 2008).

Quando envolve o trato respiratório superior ocorrem espirros, secreção nasal e uma tumefação subcutânea na região do focinho, sendo essa forma da criptococose mais comum em felinos do que em cães (Medleau e Hnilica, 2009). Também pode ocorrer deformidade dos ossos nasais subjacentes e lesões em forma de massas granulomatosas, as quais podem se exteriorizar pelas narinas (Sherding, 2008).

A síndrome neurológica, é mais comum em cães (Marcasso et al., 2005). O animal pode apresentar sinais como: depressão, alteração de comportamento, convulsões, andar em círculos, ataxia, perda de sensação de olfato e paresia, dependendo do local da lesão (Marcasso et al., 2005; Nelson e Couto, 2015). A infecção pode prevalecer nas meninges, no encéfalo, na medula ou nos nervos periféricos (Pereira e Coutinho, 2003).

$\mathrm{Na}$ forma ocular da criptococose é comum haver perda progressiva da visão (Honsho et al., 2003), mas o animal também pode apresentar quadros de coriorretinite granulomatosa, hemorragia retineana, edema papilar e neurite óptica e midríase (Larsson et al., 2003). As manifestações oculares da criptococose, na sua maioria, fazem parte do quadro clínico da doença do sistema nervoso central (Moretti et al., 2008)

A síndrome cutânea é menos comum em cães, ocorre preferencialmente na pele da cabeça e pescoço (Marcasso et al., 2005) e caracteriza-se por pápulas e nódulos indolores múltiplos, que podem ulcerar (Medleau e Hnilica, 2009) e apresentar secreção serosa (Nelson e Couto, 
2015). Erosões, úlceras e fístulas em focinho, língua, gengiva, palato e lábios são verificadas em cerca de $20 \%$ dos cães doentes (Pereira e Coutinho, 2003). Tal aspecto ulcerativo é bastante típico nos felinos, constituindo-se numa das formas da síndrome LECMN (leishmaniose esporotricose-criptococose-micobacterioseneoplasia) que, pelas lesões similares, deve sempre ter sua ocorrência averiguada na clínica dermatológica de gatos e cães (Larsson, 2003).

A anamnese e avaliação física são importantes para a suspeita clínica, mas o diagnóstico definitivo é baseado em testes de antígeno, histopatológico e micológico (citológico e cultura), sendo este considerado padrão ouro (Nelson e Couto, 2015). O diagnóstico é realizado por meio de exames citológicos, histopatológicos e cultura fúngica para identificação do microrganismo (Crivellenti e Crivellenti, 2015). ELISA (Enzyme Linked Immunosorbent Assay) e teste de aglutinação em látex para pesquisa de material capsular de $C$. neoformans podem ser usados para diagnóstico, porém em infecções de caráter não sistêmico os resultados de testes sorológicos podem ser negativos (Medleau e Hnilica, 2009). Assim, são necessários exames citológicos e de isolamento fúngico que contribuam com uma identificação mais específica dos agentes etiológicos para posteriormente ser feita a seleção de uma terapia apropriada, já que a maioria das micoses ocasionam sinais clínicos inespecíficos (Blanco e Garcia, 2008).

O isolamento fúngico é feito a partir de exsudato, líquido cérebro espinhal (LCR), líquido sinovial e amostras teciduais semeadas nos meios clássicos (ágar Sabouraud simples e Sabouraud com cloranfenicol e cicloexamida) (Larsson et al., 2003). De acordo com Medleau e Hnilica (2009), nas infecções localizadas os testes de ELISA podem ser negativos.

O teste sorológico para o diagnóstico da criptococose é sensível, específico, e permite um diagnóstico rápido e seguro (Pedroso e Candido, 2006). Normalmente, estes testes são realizados com "kits" comerciais, sendo o mais empregado para a detecção de antígenos criptocócicos o teste da aglutinação em látex (Pereira e Coutinho, 2003), esse teste também pode ser usado para monitorar a resposta ao tratamento. O teste ELISA detecta antígenos em títulos mais baixos e mais precocemente na infecção por Cryptococcus, podendo ser realizado a partir de amostras de soro, urina ou líquor (Pereira e Coutinho, 2003).

O tratamento é sistêmico e com tempo inespecífico, mantendo-o durante, no mínimo 30 ou 60 dias após cura clínica completa e, quando possível deve-se fazer a extirpação cirúrgica das lesões cutâneas (Medleau e Hnilica, 2009). A terapia de escolha depende da disponibilidade do fármaco, da localização da infecção e dos efeitos colaterais que podem ser observados em cada animal (Montoya e Zamora, 2009). Em relação aos protocolos de terapia recomendados, são indicados antifúngicos (poliênicos, azólicos e pirimidínicos) sistêmicos como anfotericina $\mathrm{B}$, fluocitosina, cetoconazol, itraconazol, fluoconazol, isoladamente ou em associações, a exemplo de cetoconazol-fluocitosina, anfotericina B-fluocitosina (Larsson et al., 2003).

O objetivo deste trabalho é relatar um caso de criptococose cutânea em uma cadela de 9 anos de idade de raça Pastor Alemão.

\section{Descrição do Caso}

\section{Identificação do animal}

Uma cadela de 9 anos de idade, raça Pastor Alemão, pesando $23 \mathrm{~kg}$ foi atendida na Unidade Hospitalar Veterinária (UHV) da Universidade Estadual do Ceará (UECE) no dia 21 de julho de 2015. As principais queixas do tutor eram de que o animal havia perdido peso e presença de lesões no membro torácico esquerdo (MTE) que não cicatrizavam (Figura 1).

\section{Anamnese}

$\mathrm{O}$ tutor informou que morava em Cabo Frio-RJ e havia trazido a cadela para Fortaleza há poucos meses. Além disso, o animal tinha o hábito de bater o membro torácico esquerdo em um portão, causando lesões frequentes. Relatou ainda que na semana anterior já havia levado a cadela em outra clínica, onde foi solicitado teste rápido para Leishmaniose (Leishmaniose Ac Test $\mathrm{Kit}^{\circledR}$ ) cujo resultado foi negativo e o animal usava coleira repelente $\left(\right.$ Scalibor $\left.^{\circledR}\right)$.

A alimentação da cadela era à base de ração comercial e restos de comida do tutor, a vermifugação e vacinações para raiva e doenças virais estavam em dia, mas não possuía vacinação contra leishmaniose. $\mathrm{O}$ ambiente em que a mesma ficava tinha areia e frequentemente apareciam morcegos no canil onde ela e mais outra cadela, que não apresentava sintomas, dormiam. 


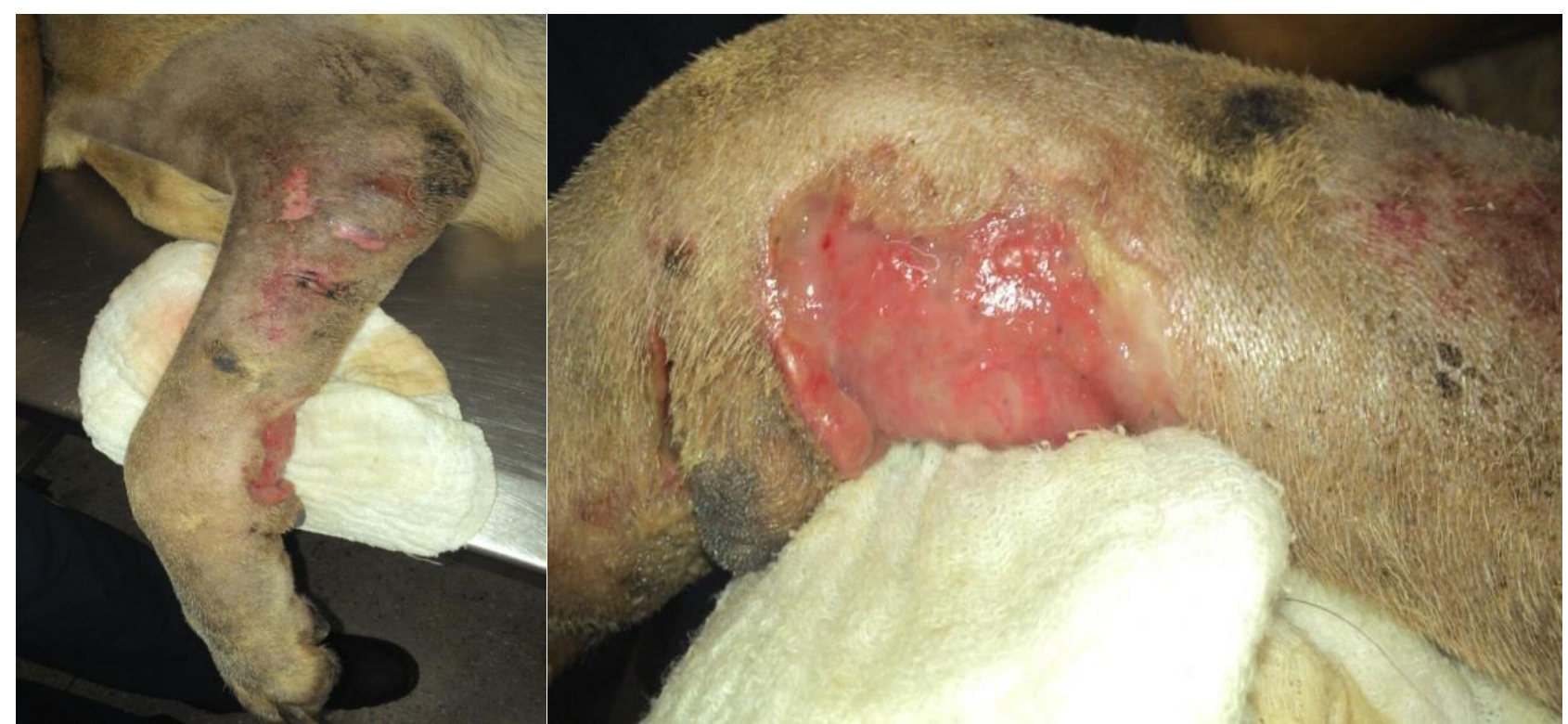

Figura 1. Membro torácico esquerdo (MTE) de uma cadela de 9 anos de idade, raça Pastor Alemão, com lesões ulceradas no primeiro dia de atendimento.

\section{Exame clínico}

$\mathrm{Na}$ avaliação física o animal apresentava mucosas normocoradas, temperatura retal de $38,9^{\circ} \mathrm{C}$, frequência cardíaca de 110 batimentos por minuto e respiratória de 30 movimentos respiratórios por minuto, linfonodos préescapulares aumentados e foram visualizadas lesões ulcerativas e desconforto no MTE, pois o animal tentava morder ao examinar o membro.

Suspeitando tratar-se de fratura foi solicitada uma radiografia do MTE, em seguida foi prescrito dipirona na dosagem de $20 \mathrm{mg} / \mathrm{kg}$ por via oral $(\mathrm{VO})$ a cada 8 horas (q8h) até o retorno no dia seguinte.

No outro dia, o tutor retornou com o laudo da radiografia onde foi descrito que os ossos rádio e ulna estavam dentro dos limites da normalidade radiográfica, no entanto havia acentuado aumento de volume em partes moles ao redor de todo o MTE. Também foi descrito deslocamento do sétimo e oitavo sesamoide do quinto metacarpo do MTE. Descartada a hipótese de fratura foi indicada colheita de material da lesão para realização de TSA (Teste de Sensibilidade aos Antimicrobianos), cultura fúngica e citologia das lesões.

Após 11 dias, foi realizada colheita de material para exames micológicos (cultura e citologia), bacteriológicos e TSA. Para isso fez-se um imprint da área acometida (pressionando uma lâmina de vidro tamanho $15 \times 40 \mathrm{~mm}$ limpa sobre a ferida exposta) e coleta de secreção da lesão com swabs estéreis acondicionados dentro de um tubo de ensaio contendo solução de cloreto de sódio
$0,9 \%$ e, imediatamente, as amostras foram enviadas para o Laboratório de Microbiologia da Faculdade de Veterinária da Universidade Estadual do Ceará (FAVET - UECE).

Foi relatado que a cadela estava com hiporexia e tinha dificuldade de apoiar o MTE. Na palpação do membro observou-se edema, desconforto na região proximal e as lesões continuavam com características ulcerativas com conteúdo seroso (Figura 2). Como o animal continuava com dificuldade de apoiar o MTE, foram solicitados raio $\mathrm{X}$ incluindo a área da articulação escápulo-umeral, raio X de tórax para avaliação pré-anestésica e uma biópsia para realização de exame histopatológico para descartar diagnóstico de neoplasma.

Foi prescrito meloxicam $(0,1 \mathrm{mg} / \mathrm{kg})$ via oral (VO) a cada 24 horas (q24h) por 5 dias, cloridrato de tramadol $(2 \mathrm{mg} / \mathrm{kg})$ VO a cada 8 horas (q8h) durante 3 dias e enrofloxacina $(5 \mathrm{mg} / \mathrm{kg}) \mathrm{VO}$, a cada 12 horas (q12h) durante 10 dias. Além disso, foi indicada a aplicação tópica de pomada a base de digluconato de clorexidina $0,7 \mathrm{~g}$ duas vezes ao dia após limpeza da lesão com solução fisiológica $0,9 \%$.

\section{Diagnóstico}

Com base na anamnese, sinais clínicos e resultados dos exames micológicos, bacteriológicos, histopatológico e radiológicos foi confirmado o diagnóstico de criptococose. No exame bacteriológico não foram visualizadas bactérias na amostra enviada, consequentemente, o TSA não foi realizado. 


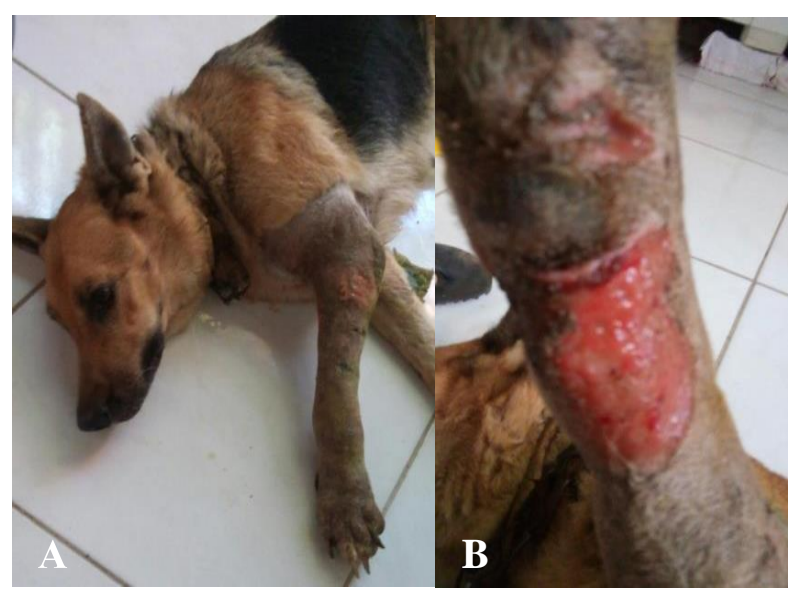

Figura 2. A. Pastor-alemão, nove anos, com membro torácico esquerdo edemaciado e lesão em região próxima ao cotovelo. B. Membro torácico esquerdo com lesão erosiva e avermelhada.

No novo exame radiográfico foi visualizado aumento de volume em partes moles ao redor do rádio e ulna indicando edema. $\mathrm{Na}$ área de articulação escápulo-umeral esquerda foram visualizadas interlinhas radiotransparentes com presença de discretos osteófitos em bordo caudal da cavidade glenoide, sendo compatível com artrose.

O exame micológico direto corado com Gram e Panótico, colorações disponíveis no laboratório, revelou a presença de leveduras capsuladas compatíveis com Cryptococcus spp. A cultura fúngica em ágar Sabouraud simples revelou crescimento puro de Cryptococcus spp. o qual foi confirmado por testes bioquímicos.

\section{Tratamento}

Com o resultado do exame indicando um quadro de criptococose deu-se início à terapia com itraconazol na dosagem de $10 \mathrm{mg} / \mathrm{kg}$, VO (q24h), durante 60 dias (recomendando fornecer o fármaco junto com a alimentação) e continuar a aplicação de pomada a base de digluconato de clorexidina após limpeza das feridas.

Passados 15 dias desde o início da terapia antifúngica, a cadela foi levada ao hospital para realização da biópsia. Como medicação préanestésica foi aplicado $0,5 \mathrm{mg} / \mathrm{kg}$ de metadona, por via intramuscular (IM) e para a anestesia geral foi feita uma Anestesia Total Intravenosa (TIVA) com infusão contínua de $0,5 \mathrm{mg} / \mathrm{kg} / \mathrm{min}$ (IV) de propofol.

Na biópsia, foi colhido um fragmento de músculo, que media $0,3 \times 0,3 \times 0,2 \mathrm{~cm}$, pardacento conservado para fixação em formalina a $10 \%$, a amostra foi encaminhada para um laboratório particular para análise histopatológica. No laudo de exame histopatológico constava que as secções histopatológicas mostraram edema discreto e infiltração inflamatória constituída por linfócitos, macrófagos e neutrófilos, porém sem sinais de malignidade, indicando miosite. Na amostra não foi realizada nenhuma outra técnica de coloração especial para pesquisa micológica.

No pós-cirúrgico, foram prescritos cefalexina $(30 \mathrm{mg} / \mathrm{kg}, \mathrm{VO}, \mathrm{q} 12 \mathrm{~h})$ durante 10 dias, dipirona $(20 \mathrm{mg} / \mathrm{kg}, \mathrm{VO}, \mathrm{q} 8 \mathrm{~h})$ durante 3 dias e omeprazol $(1 \mathrm{mg} / \mathrm{kg}$ VO, q24h) por 3 dias. Permaneceu-se a terapia com itraconazol (10mg/kg VO q24h).

Dezoito dias após a biópsia a paciente retornou para avaliação de rotina. No exame físico foi observado que havia mais uma lesão, semelhante à do MTE, no membro posterior direito. A cadela continuava com hiporexia, mas relatou-se que as fezes, urina e ingestão hídrica permaneciam normais.

Foi feita colheita de sangue da veia jugular utilizando seringa de $5 \mathrm{~mL}$ agulha $30,0 \times 0,8 \mathrm{~mm}$ que foi enviada para análise no laboratório de Patologia Clínica da FAVET/UECE para realizar hemograma completo e dosagens de creatinina e alanina-aminotransferase (ALT).

Como o animal ainda claudicava e tinha histórico de artrose, foi prescrito meloxicam $0,2 \mathrm{mg} / \mathrm{kg}$ VO, q24h por 7 dias e vitamina E (10 $\mathrm{UI} / \mathrm{kg} / \mathrm{animal}$, q24h, por 30 dias). A dose de itraconazol foi ajustada para $20 \mathrm{mg} / \mathrm{kg} \mathrm{VO}, \mathrm{q} 24 \mathrm{~h} \mathrm{e}$, após isso, as lesões regrediram significativamente.

$\mathrm{O}$ animal estava sendo tratado com itraconazol na dosagem de $20 \mathrm{mg} / \mathrm{kg} \mathrm{VO}$, q24h, há cinco meses. Segundo o tutor, a cadela passou a alimentar-se melhor, as lesões melhoraram consideravelmente (Figura 3). Foi marcado novo retorno, mas o tutor não trouxe o animal no hospital para reavaliação.

\section{Discussão}

Estudos mostraram que nos casos de criptococose canina a grande maioria está relacionada a alterações do sistema nervoso central (Honsho et al., 2003). Entretanto, neste relato ocorreu a forma cutânea. Lester et al. (2004) avaliaram 38 casos de criptococose, sendo $15(39,5 \%)$ em cães. Dentre estes, $9(60 \%)$ apresentaram sinais neurológicos, $2 \quad(13,3 \%)$ apresentaram alterações oculares, e 3 (20\%) sinais de trato respiratório superior. 


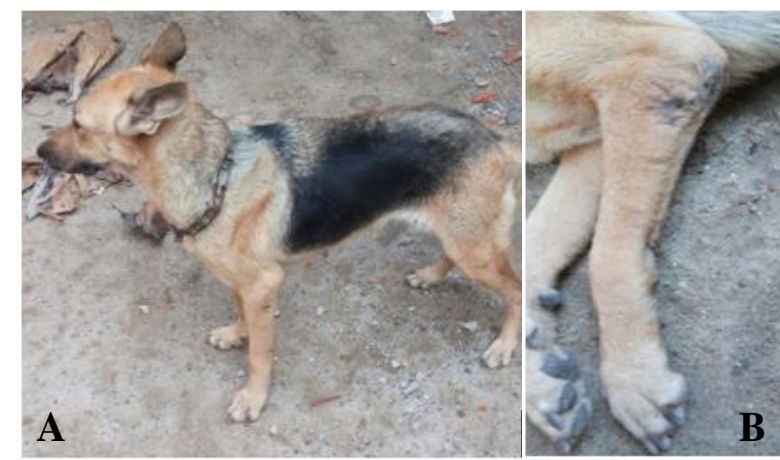

Figura 3. A. Canina em domicílio do tutor após cinco meses de terapia. B. Membro torácico esquerdo com significativa melhora das lesões, imagem enviada pelo tutor.

McGill et al. (2009) observaram em seu estudo que $53,6 \%$ dos 57 cães estudados eram fêmeas e a idade dos cães acometidos variou entre 11 meses e 12 anos, com média de 2,5 anos, sendo os animais em sua maioria jovens adultos, diferente do presente caso, que se trata de uma fêmea de meia-idade.

A criptococose cutânea primária é pouco frequente, uma vez que as lesões cutâneas geralmente são acompanhadas de uma infecção sistêmica. Há evidências de que a infecção cutânea primária por Cryptococcus sp. ocorra por inoculação direta do microrganismo em locais de dano celular ou trauma (Khodakaram-Tafti e Dehghani, 2006; Pau et al., 2010; Martins et al., 2014). A forma cutânea primária de criptococose pode ocorrer indiferente do paciente ser imunocompetente ou imunocomprometido, (Christianson et al., 2003; Martins et al., 2014).

Úlceras cutâneas em região de cavidade oral, nariz e lábios são as formas mais comuns. A lesão cutânea em geral é caracterizada por múltiplas pápulas e nódulos que podem ulcerar, mas não há sinais de dor quando as lesões são palpadas (Medleau e Hnilica, 2009). No entanto, neste relato as úlceras cutâneas quando palpadas causavam incômodo no animal.

A criptococose cutânea é de difícil diagnóstico do ponto de vista clínico em virtude da baixa casuística, sendo pouco incluída pelos veterinários no diagnóstico diferencial de dermatopatias (Larsson et al., 2003) e porque as lesões de pele não são patognomônicas, variando de nódulos a úlceras e placas (Allegue et al., 2007; Martins et al., 2014).

O diagnóstico é realizado através da citologia, histopatologia e cultura fúngica para identificação do microrganismo (Crivellenti e Crivellenti, 2015). ELISA e teste de aglutinação em látex para pesquisa de material capsular de C. neoformans podem ser usados para diagnóstico, porém em infecções localizadas fora do SNC esses testes fornecem menor eficácia na detecção de antígeno (Medleau e Hnilica, 2009).

No relato de caso foi realizado exame direto do imprint corado com Gram e Panótico, pois anteriormente não havia suspeitas de criptococose, mas mesmo sem a disponibilidade do corante ideal (tinta nanquim) foram visualizadas estruturas fúngicas compatíveis com Cryptococcus spp. Segundo Rondelli et al. (2010) o imprint é uma técnica relativamente simples e pode colaborar para estabelecer diagnóstico adequado, diminuindo as chances de terapêuticas inadequadas.

No resultado da cultura fúngica (feita em ágar Sabouraud simples e Sabouraud com cloranfenicol e cicloexamida) foi observado o crescimento de colônias de Cryptococcus spp. somente no meio de cultivo Sabouraud sem cicloexamida semelhante ao que relata Quinn et al. (2005) que confirmou o crescimento de Criptococcus neoformans em cultura fúngica, utilizando-se ágar Sabouraud simples ou adicionado de cloranfenicol e cicloexamida. A cultura fúngica é considerada $\mathrm{o}$ teste comprobatório da criptococose (Moretti et al., 2008) e conforme Vorathavorn et al. (2013) esse exame é bastante sensível, sendo fundamental para a confirmação do diagnóstico.

Os exames solicitados para o diagnóstico de criptococose neste estudo foram semelhantes aos empregados por Larsson et al. (2003) no Serviço de Dermatologia do Hospital veterinário da Universidade se São Paulo HOVET/USP, ou seja, exame físico, cultura fúngica, histopatologia de pele e estudo radiográfico das regiões acometidas.

A cultura bacteriana da secreção dérmica não evidenciou bactérias na amostra, sendo assim o TSA não se aplicou. O referido exame foi solicitado no intuito de descartar uma possível infecção bacteriana após trauma relatado pelo proprietário.

$\mathrm{Na}$ descrição microscópica do laudo as secções histopatológicas de músculo mostraram edema discreto e infiltração inflamatória constituída por linfócitos, macrófagos e neutrófilos, focos de hemorragia não havendo sinais de malignidade. O que está de acordo com os resultados encontrados por Rondelli et al. (2010) que verificaram reação inflamatória com predomínio de linfócitos, histiócitos, macrófagos 
e células gigantes, bem como a formação de granulomas em alguns casos.

O hemograma completo do animal estudado encontrava-se dentro do parâmetro de normalidade, corroborando os resultados encontrados por Sherding (2008). A análise bioquímica do animal não demonstrou alterações significativas, porém de acordo com Pereira e Coutinho (2003) em pacientes tratados com itraconazol, a atividade da ALT deve ser monitorada a cada 15 dias no primeiro mês e, em seguida a cada 30 dias, o que não foi possível no animal em questão, pois o tutor não retornou com o animal para realizar os exames.

Não foram realizados testes sorológicos para criptococose neste estudo, no entanto, segundo Nelson e Couto (2015) o resultado positivo para exame sorológico com detecção de anticorpos circulantes anti-C. neoformans não confirma o diagnóstico definitivo para a doença clínica, pois animais saudáveis podem apresentar resultados positivos e não apresentar clinicamente a doença. Os anticorpos geralmente não estão presentes durante a infecção ativa por C. neoformans e podem aparecer durante $\mathrm{o}$ tratamento e com a recuperação do paciente, sendo o exame comprobatório a cultura fúngica (Moretti et al., 2008).

Testes diagnósticos rápidos e específicos para infecções fúngicas são extremamente importantes para a eficácia no tratamento de pacientes infectados. A demora na terapia adequada está associada ao aumento da morbidade e da mortalidade (Casali et al., 2001).

$\mathrm{O}$ aspecto ulcerativo das lesões deve ser avaliado para um diagnóstico diferencial de leishmaniose, esporotricose e micobacteriose que, pelas lesões similares, deve ter sua ocorrência averiguada na clínica dermatológica de gatos e cães (Larsson et al., 2003).

O tratamento com antifúngico deve ser prescrito de acordo com o grau de infecção, levando em consideração a situação imunológica do paciente e os efeitos colaterais desses fármacos, principalmente devido à toxicidade para pacientes com lesões nos rins e fígado, órgãos responsáveis pela metabolização e eliminação de tais compostos (Pereira e Coutinho, 2003).

Neste estudo o tratamento com o itraconazol, mesmo por longo tempo evidenciou poucos efeitos adversos (somente hiporexia) o que está de acordo com Queiroz et al. (2008). Entretanto, segundo Pereira e Coutinho (2003) ao fazer o uso do itraconazol, a atividade da ALT deve ser monitorada a cada 15 dias no primeiro mês e, em seguida a cada 30 dias para avaliação de algum dano hepático ocasionado pelo uso prolongado do antifúngico.

Determinados triazóis, como o Itraconazol e o fluconazol apresentam alta disponibilidade quando administrados por via oral e boa penetração no sistema nervoso central, entretanto a utilização desses fármacos ainda não foi amplamente testada, sendo desconhecido o tempo de tratamento necessário (Pereira e Coutinho, 2003).

A falha de terapia medicamentosa pode ocorrer devido à penetração insuficiente de fármaco no órgão/sistema acometido pelo fungo, a imunidade do hospedeiro, resistência a drogas antifúngicas pelo agente, absorção prejudicada das drogas (terapia concomitante com droga bloqueadora $\mathrm{H} 2$ e itraconazol, por exemplo), comorbidades (diabetes, insuficiência cardíaca congestiva, neoplasia), ou infecção generalizada dos órgãos críticos, tais como o SNC, miocárdio, pâncreas e trato gastrointestinal. (Vorathavorn et al., 2013).

O exame micológico realizado por meio do exame direto e cultura fúngica foi $\mathrm{o}$ que consolidou o diagnóstico neste caso. Associa-se a este fato também a resposta eficaz ao tratamento pela paciente.

Apesar de ser uma zoonose, o risco de transmissão entre animais e humanos é baixo, acometendo particularmente pessoas imunocomprometidas. A via de transmissão é a mesma dos animais. Portanto, antes de varrer fezes de pássaros no solo é aconselhado utilizar água para não espalhar esporos de Cryptococcus spp. Em laboratório o contato com cultura fúngica pode apresentar risco de contágio por inalação dos esporos (Crivellenti e Crivellenti, 2015).

\section{Conclusão}

A baixa casuística da criptococose cutânea em cães e os sinais clínicos com lesões de pele semelhantes a outras enfermidades dificulta o diagnóstico. Sendo assim, foi vista a importância desse relato para divulgação do conhecimento sobre a forma cutânea da doença, permitindo a inclusão dessa forma de criptococose no diagnóstico diferencial de dermatopatias durante a rotina de atendimentos, possibilitando realizar um tratamento preciso e adequado.

O conhecimento sobre o quadro clínico da 
criptococose, associado aos exames complementares e diagnósticos mais precisos contribuem para uma terapia mais eficaz, fazendo com que esta enfermidade atualmente apresente prognósticos mais favoráveis.

\section{Conflito de interesse}

Os autores declaram não existir conflito de interesse

\section{Referências}

Allegue, F.; Lis, M.P.; Álvarez, R.P. Primary cutaneous cryptococcosis presenting as a whitlow. Acta Dermato Venereologica, 87(5): 443-444, 2007.

Bivanco, F.C.; Machado, C.A.; Martins, E.L. Criptococose cutânea. Arquivos Médicos do ABC, 31(2): 102-109, 2006.

Blanco, J.L.; Garcia, M.E. Immune response to fungal infections. Veterinary Immunology and Immunopathology, 125(1): 47-70, 2008.

Casali, A.K.; Staats, C.; Schrank, A.; Vainstein, M.H. Cryptococcus neoformans: aspectos moleculares e epidemiologicos. Revista Biotecnologia Ciência e Desenvolvimento, 20: 34-37, 2001.

Christianson, J.C.; Engber, W.; Andes, D. Primary cutaneous cryptococcosis in immunocompetent and immunocompromised hosts. Medical Mycology, 41(3): 177-188, 2003.

Crivellenti, L.Z.; Crivellenti, S.B. Casos de rotina em medicina veterinária de pequenos animais. 2a ed. São Paulo: MedVet, 2015. $842 p$.

Grace, S.F. Criptococose. In: Norsworthy, G.D.; Crystal, M.A.; Grace, S.F.; Tilley, L.P. O paciente felino. $3^{\mathrm{a}}$ ed. São Paulo: Roca, 2009. p. 56-59.

Honsho, C.S.; Mine, S.Y.; Oriá, A.P.; Benato, N.; Camacho, A.A.; Alessi, A.C.; Laus, J.L. Generalized systemic cryptococcosis in a dog after immunosuppressive corticotherapy. Arquivo Brasileiro de Medicina Veterinária e Zootecnia, 55(2): 155-159, 2003.

Juliano, R.S.; Souza, A.I.; Scheide, R. Criptococose felina. Revista de Patologia Tropical, 35(1): 65-70, 2006.

Khodakaram-Tafti, A.; Dehghani, S. Cutaneous cryptococcosis in a donkey. Comparative Clinical Pathology, 15: 271-273, 2006.

Larsson, C.E.; Otsuka, M.; Michalany, N.S.; Barros, P.S.M.; Gambale, W.; Safatle, A.M.V. Criptococose canina: relato de caso. Arquivo
Brasileiro de Medicina Veterinária e Zootecnia, 55(5): 533-538, 2003.

Lester, S.J.; Kowalewich, N.J.; Bartlett, K.H.; Krockenberger, M.B.; Fairtfax, T.M.; Malik, R.; Clinicopathologic features of an unusual outbreak of cryptococcosis in dogs, cats, ferrets, and a bird: 38 cases. Journal of the American Veterinary Medical Association, 225(11): 1716-1722, 2004.

Marcasso, R.A.; Sierra, S.; Arias, M.V.B.; Bracarense, A.P.F.R.L.; Yamamura, A.A.M.; Biasi, F.; Lopes, B.A.; Amude, A.M.; Cortêz, D.E.A. Criptococose no sistema nervoso de cães - relato de três casos. Semina: Ciências Agrárias, 26(2): 229-23, 2005.

Martins, D.B.; Deckmann, M.A.J.; Sperotto, V.R. Cutaneous cryptococcosis associated with severe infestation by Sarcoptes sp. and Demodex sp. in a dog. Ciência Rural, 44(8): 1437-1441, 2014.

McGill, S.; Malik, R.; Saul, N.; Beetson, S.; Secombe, C.; Robertson, I.; Irwin, P. Cryptococcosis in domestic animals in Western Australia: a retrospective study from 1995-2006. Medical Mycology, 47(6): 625639, 2009.

Medleau, L.; Hnilica, K.A. Dermatologia de pequenos animais. Atlas colorido e guia terapêutico. $2^{\mathrm{a}}$ ed. São Paulo: Roca, 2009. $512 \mathrm{p}$.

Montoya, Z.M.; Zamora, V.G. Isolamento de Cryptococcus neoformans var. grubii em um felino doméstico-relato de caso. Revista de Medicina Veterinária, 18: 53- 61, 2009.

Moretti, M.L.; Resende, M.R.; Lázera, M.D.S.; Colombo, A.L.; Shikanai-Yasuda, M.A. Consenso em criptococose - 2008. Revista da Sociedade Brasileira de Medicina Tropical, 41(5): 524-544, 2008.

Nelson, R.W.; Couto, C.G. Medicina interna de pequenos animais. $5^{\text {a }}$ ed. Rio de Janeiro: Elsevier, 2015. 1474p.

Pau, M.; Lallai, C.; Aste, N.; Atzori, L. Primary cutaneous cryptococcosis in an immunocompetent host. Mycoses, 53(3): 256258, 2010.

Pedroso, R.S.; Candido, R.C. Diagnóstico laboratorial da criptococose. Newslab, 77: 94102, 2006.

Pereira, A.P.C., Coutinho, S.D.A. Criptococose em cães e gatos - revisão. Clínica Veterinária, 45: 24-32, 2003. 
Queiroz, J.P.A.F.; Sousa, F.D.N; Lage, R.A.; Izael, M.A.; Santos, A.G. Criptococose - Uma revisão bibliográfica. Acta Veterinaria Basilica, 2(2): 32-38, 2008.

Quinn, P.J.; Markey, B.K.; Carter, M.E.; Donnelly, W.J.; Leonard. F.C. Microbiologia veterinária e doenças infecciosas. Porto Alegre: Artmed, 2005. 512p.

Rondelli, M.C.H.; Nogueira, A.F.S.; Anai, L.A.; Gava, F.N.; Borin, S. Criptococose diagnosticada por imprints de lesões em mucosa oral em cão. Arquivo Brasileiro de
Medicina Veterinária e Zootecnia, 62(5): 1271-1274, 2010.

Sherding, R.G.; Micoses sistêmicas. In: Bichard, S.J.; Sherding, R.G. Manual saunders: clínica de pequenos animais. $3^{\text {a }}$ ed. São Paulo: Roca, 2008. p.209-222.

Vorathavorn, V.I.; Sykes, J.E.; Feldman, D.G. Cryptococcosis as an emerging systemic mycosis in dogs. Journal of Veterinary Emergency and Critical Care, 23(5): 489497, 2013. 